\title{
DLL4 expression is a prognostic marker and may predict gemcitabine benefit in resected pancreatic cancer
}

\begin{abstract}
A Drouillard ${ }^{1,2,7}$, F Puleo ${ }^{3,7}$, J B Bachet ${ }^{4}$, S Ouazzani $^{3}$, A Calomme $^{3}$, P Demetter $^{5}$, G Verset $^{3}$, J L Van Laethem ${ }^{3}$ and R Maréchal ${ }^{\star, 3,6}$

${ }^{1}$ Department of Gastroenterology and Digestive Oncology, University Hospital of Dijon, Dijon, France; ${ }^{2}$ Digestive Cancer Registry of Burgundy, INSERM U866, University Hospital of Dijon, Dijon, France; ${ }^{3}$ Department of Gastroenterology and Digestive Oncology, Erasme Hospital, Brussels, Belgium; ${ }^{4}$ Department of Hepatogastroenterology, Pitié Salpêtrière Hospital, APHP, Paris, France; ${ }^{5}$ Department of Pathology, Erasme Hospital, Brussels, Belgium and ${ }^{6}$ Laboratory of Experimental Gastroenterology, Université Libre de Bruxelles, Brussels, Belgium
\end{abstract}

Background: There is an increasing interest for Notch signalling pathway and particularly Delta-like ligand 4 (DLL4) as potential therapeutic target to improve outcome for patients with pancreatic ductal adenocarcinoma (PDAC).

Methods: Using immunohistochemistry (IHC) and tissue microarray (TMA), we assessed the expression patterns of DLL4, Notch1 and Notch3 in 151 patients from two independent cohorts of resected PDAC. We investigated the prognostic and the predictive significance of these proteins.

Results: High IHC DLL4 expression in cancer cells was associated with worse overall survival (OS) and disease-free survival (DFS) than low DLL4 expression (median OS: 12.9 vs 30.4 months, $P=0.004$ and median DFS: 8.8 vs 17.4 months, $P=0.02$ ). High DLL4 expression remained a significant negative prognostic factor in multivariate analysis (HR for OS: 2.1, $P=0.02$ and HR for DFS: 2.0, $P=0.02)$. Low DLL4 abundance was associated with a longer OS-only for patients who received an adjuvant gemcitabine-based chemotherapy $(P<0.001)$ but not for patients who did not receive gemcitabine $(P=0.72)$. Furthermore, the interaction test for adjuvant gemcitabine therapy was statistically significant $(P<0.001)$. The validating cohort recapitulated the findings of the training cohort.

Conclusions: Low DLL4 abundance in tumour cells may predict the benefit from adjuvant gemcitabine therapy after PDAC resection.

Pancreatic ductal adenocarcinoma (PDAC) is one of the most lethal malignancies with a 5 -year survival rate $<5 \%$ and represents the fourth leading cause of cancer-related mortality worldwide. This poor prognosis could be explained by the relative low rate of potentially curative resection and a high rate of post-surgery recurrence due to histological aggressiveness and to chemoresistance. Therefore, to improve outcome of patients with PDAC, a current approach relies on the identification of molecular prognostic biomarkers and specific signalling pathways to stratify recurrence risks and to identify new potential therapeutic targets. Recently, there has been an increasing interest on Notch signalling pathway, particularly Delta-Like Ligand 4 (DLL4), as prognostic biomarkers and new therapeutic target in many solid tumours, including PDAC. The Notch signalling pathway, which is composed by four transmembrane receptors (Notch1-4) and five ligands (Jagged 1, 2, Delta-like ligands 1, 3 and 4), is involved in

\footnotetext{
*Correspondence: Dr R Maréchal; E-mail: raphael.marechal@erasme.ulb.ac.be

${ }^{7}$ These two authors contributed equally to this work.
}

Received 4 March 2016; revised 16 August 2016; accepted 14 September 2016; published online 18 October 2016

(c) 2016 Cancer Research UK. All rights reserved 0007-0920/16 
several steps of tumour carcinogenesis (Mullendore et al, 2009) and tumour behaviour. Further studies have reported that activation of notch pathway is implicated in tumour progression and cell migration (Sahlgren et al, 2008), tumour cell differentiation (Hald et al, 2003; Miyamoto et al, 2003), stem cells enrichment, angiogenesis (Dufraine et al, 2008; Kofler et al, 2011) and chemoresistance. The main Notch Ligand, DLL4, is overexpressed in tumour vasculature and tumour cells to activate Notch pathway (Patel et al, 2005) and plays a key role as a regulator for tumour angiogenesis (Li et al, 2007). Several studies in both cancer models and cell lines have demonstrated that blocking DLL4 inhibits tumour growth by altering the tumour vascularisation (NogueraTroise et al, 2006; Ridgway et al, 2006; Scehnet et al, 2007) and reduces cancer stem cell frequency (Hoey et al, 2009). In a pancreatic cancer cell line, blockage of DLL4 was associated with a reduction of tumour volume, a decrease in vascular density and the inhibition of neovascularization (Oishi et al, 2010). Furthermore, a previous study showed that overexpression of DLL4 induced chemoresistance in pancreatic cancer cell line by promoting epithelial-mesenchymal transition (Kang et al, 2013). Targeting DLL4/Notch pathway was recently investigated with Demcizumab (OMP-21M18), a humanised IgG2 anti-DLL4 antibody. Interesting preliminary data have been reported in a phase I trial which is evaluating Demcizumab in patients with previously treated solid tumours, including PDAC (Smith et al, 2014). In this study, 64\% of patients treated with Demcizumab had stable disease or partial response. A randomisation phase II trial is currently ongoing, in first-line therapy of metastatic PDAC in association with gemcitabine and nabpaclitaxel (https://clinicalTrials.gov/ct2/show/ NCT02289898). However, the real prognostic significance of DLL4 in patients with resected PDAC has been less explored and, to our knowledge, no studies have evaluated the potential role of DLL4 to predict chemosensitivity to gemcitabine-based adjuvant therapy.

The aim of this study was to investigate the prognostic impact of DLL4 expression and Notch receptor expression after curative resection of PDAC and their potential role in predicting a benefit from gemcitabine-based adjuvant therapy.

\section{MATERIALS AND METHODS}

Patients and tissues. This study included two independent cohorts (the Brussels training cohort $n=86$ and the Paris validation cohort $n=68$ ) of consecutive and unselected patients with primary PDAC who had undergone curative surgery between September 1998 and August 2008 in Erasme University Hospital (Brussels cohort) and in Pitié-Salpêtrière Hospital. Exclusion criteria included macroscopically incomplete resection (R2), preoperative chemotherapy or chemoradiotherapy, tumour histology other than ductal pancreatic adenocarcinoma and patients who died in the 30 days following surgery. Sociodemographic, clinicopathological and treatment data for each patient were collected from their medical records. After surgery, all of the patients had received a regular follow-up with physical, blood and tomography examinations every 2 months during the first 6 months and then every 3 months. Vital status was obtained prospectively from the medical records and regular contact with patients. For each patient, two formalin-fixed paraffin embedded (FFPE) tissue blocks representative of the tumour were selected by a pathologist.

Tissue microarray (TMA) constitution. Tissue cores were obtained from FFPE, and slides of each case were reviewed by a pathologist after coloration with haematoxylin and eosin. Six tissue cores of $0.6-\mathrm{mm}$ diameter in each of two representative areas of the tumour (invasive margin and tumour bulk) were selected and sampled.
Immunohistochemistry. Immunohistochemical staining of FFPE tumour tissue was performing using rabbit polyclonal antibodies against DLL4 (ab7280, Abcam, UK; dilution 1:200), Notch1 (ab27526, Abcam, UK; dilution 1:100), Notch3 (sc5593, SantaCruz, US; dilution 1:25) and Vascular Endothelial Growth Factor (VEGF) (rb9031, Labvision corporation, Belgium; dilution $1: 100)$. Antigen retrieval was performed by microwave pretreatment in EDTA buffer for $15 \mathrm{~min}$ for Notch3 and in citrate buffer for $10 \mathrm{~min}$ for DLL4, Notch1 and VEGF. Renal tissue was used as positive control for DLL4 expression, colon tissue for Notch1 and Notch3, and colon cancer tissue for VEGF expression. Irrelevant rabbit IgG antibodies were applied to negative control.

Immunohistochemistry scoring. The TMA slides were captured digitally, stored as high-resolution images files using the NanoZoomer 2.0-HT slide scanner (hamatsu Photonics K.K., Hamutu city, Japan) and analysed using the NDP.view software. The tissue specimens were scored independently by two pathologists blinded to the clinicopathological data and outcome of the patients. In cases of disagreement between the two observers, the slide was reevaluated in anatomopathologic staff to obtain consensus. Then, DLL4 in tumour cells and VEGF expression were visually quantified according to the extent (percentage of staining tumour cells) and the intensity (no, low and high) of staining: a score of 0 was defined as staining in $<5 \%$ of tumour cells, a score of 2 was defined as high staining intensity in $>50 \%$ of tumour cells and a score of 1 was assigned to remaining cases. Second, we generated a scoring system based on this quantification. We divided membrano-cytoplasmic expression into two subgroups: the low expression group (score $0-1$ ) and the high expression group $($ score $=2)$. Nuclear expression of Notch1 and Notch3 was considered positive if $>5 \%$ of tumour cells were stained, regardless of staining intensity. A minimum of two spots containing tumour cells has to be evaluable to quantify expression; in their absence, expression was considered non-evaluable. All three immunohistochemical factors were tested in the Brussels training cohort but only the one that was prognostic/predictive was tested in the Paris validation cohort.

Statistical analyses. The primary outcome variables were overall survival (OS) and disease-free survival (DFS). OS was calculated from the date of surgery to the date of death. DFS was defined as the time between surgical resection and the date of the first recurrence. The cut-off date was 31 December 2013. Patients were censored at the last follow-up. All data analyses were carried out according to a pre-specified analysis plan. The prognostic value of the IHC factors were evaluated in the Brussels cohort and validated in the Paris cohort. The $\chi^{2}$ test was used to compare categorised data and the $t$ test or MannWhitney test was used to compare continuous variables. Median follow-up was calculated using the reverse Kaplan-Meier method. Correlations between IHC expression and clinicopathological characteristics were studied using the $\chi^{2}$ test or Fisher exact test. Survival curve analyses were estimated using KaplanMeier method and differences between them were assessed using the log-rank test. All variables with a $P$-value $<0.05$ in log-rank test were included in a multivariate Cox regression model and adjusted on tumour stage (T1-T2 vs T3), resection margins (R0 vs R1) and adjuvant therapy. The Cox proportional hazard regression model with backward stepwise selection was used for the multivariate analysis of survival and to estimate hazard ratios with their 95\% confidence intervals (CIs). Interaction tests were used to investigate whether the abundance of DLL4, Notch 1 and Notch3 protein had an impact on the efficacy of adjuvant gemcitabine-based therapy. All the statistical analyses were carried out using SAS Software. 


\section{RESULTS}

Patients' characteristics. In total, 154 patients who had undergone PDAC resection were included in our study. Demographic, clinical and histopathological variables are shown in Table 1.

Brussels cohort. There was a predominance of men (59\%) with a median age of 66 years. After surgery, 65 patients (76\%) received adjuvant treatment. Gemcitabine-based chemotherapy was the main regimen used in 55 patients (64\%). After a median follow-up of 73.6 months (95\% CI: 58-104), median DFS was 11.5 months
(95\% CI: 9.6-13.4) and median OS was 21.9 months (95\% CI: 17.3-26.6). At the end of follow-up, 58 patients (67\%) had relapsed.

Paris cohort. the majority (65\%) of the patients were men with a median age of 62 years. The median follow-up was 46.2 months (95\% CI: $37-49$ ) with $68 \%$ of relapsers. Median DFS was 15.8 months (95\% CI: 10.1-21.5) and the median OS was 34.3 months (95\% CI: 20.7-47.9). Once again, most of the patients received an adjuvant treatment and a gemcitabine-based therapy, the most frequently used (Table 1).

Immunohistochemical expression of DLL4 and correlation with clinicopathological characteristics. We observed the same level of

\section{Table 1. Patients' characteristics}

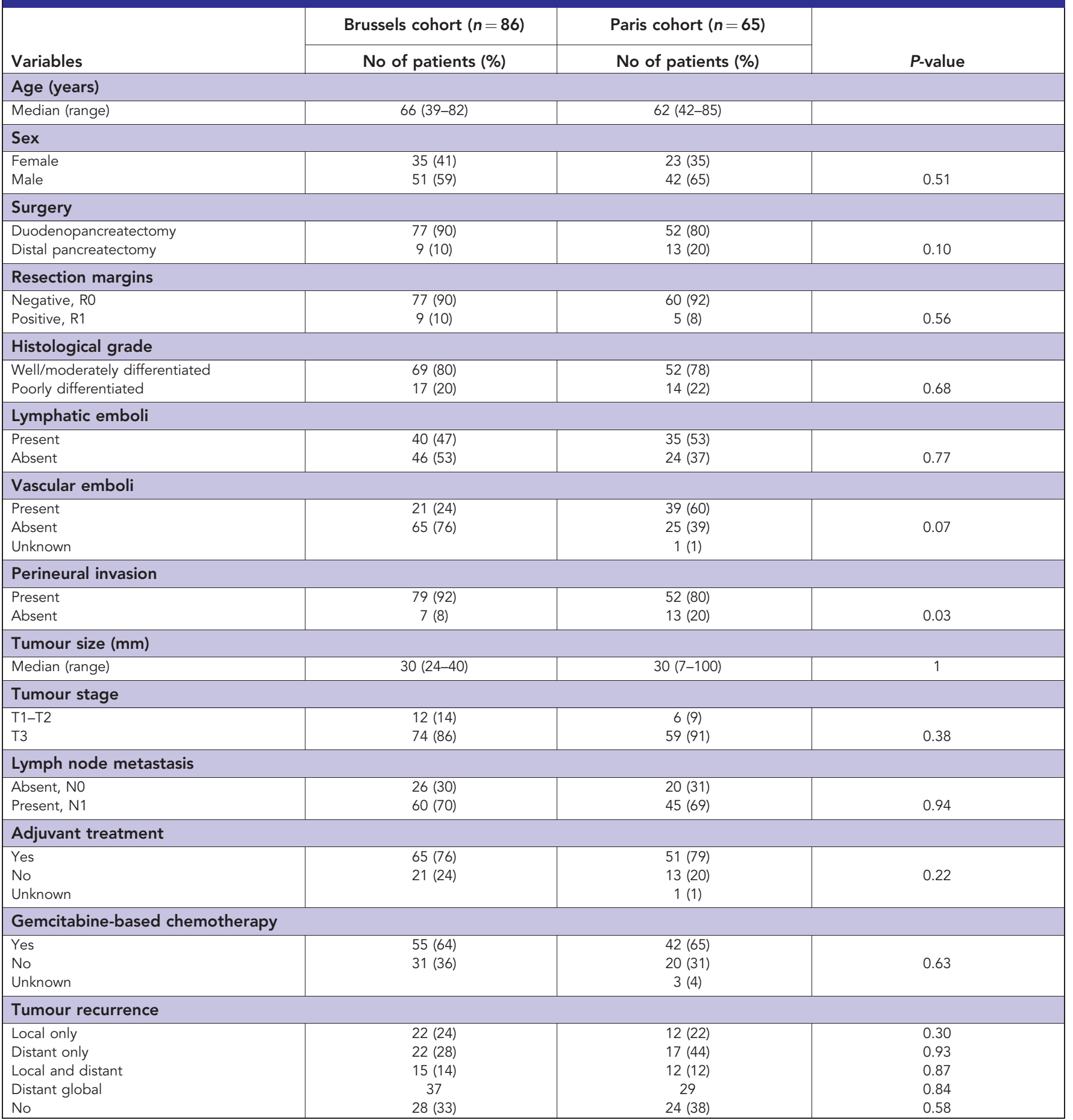


protein abundance in the tumour bulk and in the invasive margin for each of the three IHC factors (Supplementary Figure S1). Therefore, for the statistical analysis, we used a unique value of expression, which reflected the expression in these two areas. Among the Brussels cohort, IHC DLL4 expression could be evaluated in 83 patients (96\%). Interobserver agreement for DLL4 was high with an unweighted kappa score of 0.86 (95\% CI, $0.82-$ $0.90)$. tumour cell DLL4 expression was low in 33 patients (38\%) and high in 50 patients (58\%) (Table 2 and Supplementary Table S1). We found a significant association between tumour grade differentiation and DLL4 expression $(P=0.01)$. Poorly differentiated tumour was found more frequently in PDAC with high DLL4 expression than in those with low expression. None of the other clinicopathological variables, such as lymph node metastasis, tumour stage, lymphatic or vascular invasion, had a significant relationship with DLL4 expression. Moreover, DLL4 expression correlated with VEGF expression $(P=0.04$; Table 2) but not with Notch1 and Notch3 expression. Interestingly, the proportion of low and rate expressors was very similar in the validating cohort and a statistically significant association between DLL4 expression and tumour grade differentiation was also found (Supplementary Table S1).

\begin{tabular}{|c|c|c|c|}
\hline \multicolumn{4}{|c|}{$\begin{array}{l}\text { Table 2. Brussels cohort: correlation between DLL4 } \\
\text { expression in tumour cells and clinicopathological factors } \\
\qquad \begin{array}{l}\text { DLL4 expression in tumour cells }\end{array}\end{array}$} \\
\hline & $\begin{array}{c}\text { Low } n=33 \\
n(\%)\end{array}$ & $\begin{array}{c}\text { High } n=50 \\
n(\%)\end{array}$ & $P$-value \\
\hline \multicolumn{4}{|l|}{ Age } \\
\hline $\begin{array}{l}\leqslant 65 \text { years } \\
>65 \text { years }\end{array}$ & $\begin{array}{l}16(48) \\
17(52)\end{array}$ & $\begin{array}{l}24(48) \\
26(52)\end{array}$ & 1 \\
\hline \multicolumn{4}{|l|}{ Sex } \\
\hline $\begin{array}{l}\text { Female } \\
\text { Male }\end{array}$ & $\begin{array}{l}15(45) \\
18(55)\end{array}$ & $\begin{array}{l}19(38) \\
31(62)\end{array}$ & 0.65 \\
\hline \multicolumn{4}{|l|}{ Resection margins } \\
\hline $\begin{array}{l}\text { Negative, R0 } \\
\text { Positive, R1 }\end{array}$ & $\begin{array}{c}30(91) \\
3(9)\end{array}$ & $\begin{array}{r}44(88) \\
6(12)\end{array}$ & 0.74 \\
\hline \multicolumn{4}{|l|}{ Histological grade } \\
\hline $\begin{array}{l}\text { Well/mod. differentiated } \\
\text { Poorly differentiated }\end{array}$ & $\begin{array}{c}31(94) \\
2(6)\end{array}$ & $\begin{array}{l}35(70) \\
15(30)\end{array}$ & 0.011 \\
\hline \multicolumn{4}{|l|}{ Lymphatic emboli } \\
\hline $\begin{array}{l}\text { Present } \\
\text { Absent }\end{array}$ & $\begin{array}{l}15(45) \\
18(55)\end{array}$ & $\begin{array}{l}24(48) \\
26(52)\end{array}$ & 0.83 \\
\hline \multicolumn{4}{|l|}{ Vascular emboli } \\
\hline $\begin{array}{l}\text { Present } \\
\text { Absent }\end{array}$ & $\begin{array}{r}9(27) \\
24(73)\end{array}$ & $\begin{array}{l}12(24) \\
38(76)\end{array}$ & 0.80 \\
\hline \multicolumn{4}{|l|}{ Perineural invasion } \\
\hline $\begin{array}{l}\text { Present } \\
\text { Absent }\end{array}$ & $\begin{array}{c}31(94) \\
2(6)\end{array}$ & $\begin{array}{c}47(94) \\
3(6)\end{array}$ & 1 \\
\hline \multicolumn{4}{|l|}{ Tumour size $(n=59)$} \\
\hline $\begin{array}{l}\leqslant 30 \mathrm{~mm}(n=29) \\
>30 \mathrm{~mm}(n=30)\end{array}$ & $\begin{array}{r}11(55) \\
9(45)\end{array}$ & $\begin{array}{l}18(46) \\
21(54)\end{array}$ & 0.59 \\
\hline \multicolumn{4}{|l|}{ Tumour stage } \\
\hline $\begin{array}{l}\text { T1-T2 } \\
\text { T3 }\end{array}$ & $\begin{array}{r}6(18) \\
27(82)\end{array}$ & $\begin{array}{r}5(10) \\
45(90)\end{array}$ & 0.33 \\
\hline \multicolumn{4}{|c|}{ Lymph node metastasis } \\
\hline $\begin{array}{l}\text { Absent, N0 } \\
\text { Present, N1 }\end{array}$ & $\begin{array}{l}12(36) \\
21(64)\end{array}$ & $\begin{array}{l}14(28) \\
36(72)\end{array}$ & 0.47 \\
\hline \multicolumn{4}{|l|}{ VEGF expression } \\
\hline $\begin{array}{l}\text { Low } \\
\text { High }\end{array}$ & $\begin{array}{l}19(57) \\
14(43)\end{array}$ & $\begin{array}{l}17(34) \\
33(66)\end{array}$ & 0.04 \\
\hline
\end{tabular}

IHC DLL4 expression and clinical outcomes. In univariate analysis, poorly differentiated tumours, lymph node metastasis and high DLL4 expression predicted poor OS and shorter DFS after pancreatic adenocarcinoma resection (Table 3, Figures 1 and 2). Median DFS was 17.4 months (95\% CI: 10.6-22.6) for patients with low DLL4 expression $v s 8.8$ months (95\% CI: 6.8-10.4) for those with high expression $(P=0.02)$. Median OS was 30.4 months $(95 \% \mathrm{CI}$ : 21.9-49.2) and 12.9 months (95\% CI: 11.2-19.8), respectively $(P=0.004)$. In the multivariate Cox proportional model, high DLL4 expression and lymph node invasion were significant negative prognostic factors for both OS and DFS (Table 4). To independently validate the results of the training cohort, DLL4 was examined in the Paris validating cohort. Kaplan-Meier survival curves confirmed significantly reduced median overall and DFS times for high DLL4 patients as compared with low DLL4 patients (median DFS: 38.7 months (CI cannot be determined) vs 11.7 months (95\% CI: 9.3-14.0), $P=0.002$; median OS: 46.3 months (CI cannot be determined) vs 24.1 months (95\% CI: 14.1-34.1, $P=0.019$; Supplementary Table S2, Supplementary Figures S2 and S3). In multivariate analysis, DLL4 abundance remained independent and significant predictor of DFS and OS (Supplementary Table S3).

Notch1, Notch3 and VEGF expression. IHC expression could be evaluated for Notch1 in 82 patients (95\%), for Notch3 in 68 patients (79\%) and for VEGF in 84 patients (98\%). Membranocytoplasmic VEGF expression was low in 36 patients (42\%) and high in 48 patients (56\%). Concerning Notch1 and Notch3, nuclear expression was present in 10 patients (12\%) and 39 patients (45\%), respectively. Interobserver agreement was high with an unweighted kappa score of 0.82 (95\% CI, 0.79-0.85), 0.77 (95\% CI, 0.75-0.79) and 0.79 (95\% CI, 0.77-0.81) for Notch1, Notch3 and VEGF, respectively. Notch1 expression correlated significantly with lymph node metastasis $(P=0.03)$. None of these markers had a significant prognostic value for OS or DFS.

DLLA expression could predict a benefit of adjuvant gemcitabine. We investigated whether DLL4 expression indicated a benefit of the adjuvant gemcitabine-based treatment. For this, we tested the interaction between adjuvant treatment with gemcitabine-based chemotherapy and DLL4 expression in a multivariate cox proportional hazard model adjusted for stage, differentiation, resection margins and lymph node metastasis. We found a significant interaction between adjuvant treatment with gemcitabine-based chemotherapy and DLL4 expression $\left(P_{\text {(interaction) }}<0.001\right)$. This result was consistent with the Kaplan-Meier curves (Figure 2). Low DLL4 expression was associated with a longer OS than high DLL4 expression for patients who received gemcitabine-based adjuvant chemotherapy $(N=52$; log-rank test $P=0.0045)$ but not for patients who did not receive gemcitabine $(N=31$; log-rank test $P=0.72)$. No interaction was observed between gemcitabine-based adjuvant therapy and Notch1, Notch3 or VEGF expression.

The interaction between DLL4 abundance and the benefit of gemcitabine-based therapy was replicated in the Paris cohort (Supplementary Figure S3; $P_{\text {(interaction) }}=0.019$ ).

\section{DISCUSSION}

Our study evaluated the prognostic impact of several Notch pathway components in PDAC after potential curative resection, using immunochemistry assessments applied to TMA technologies. Our data showed a strong relationship between DLL4 protein abundance in cancer cells and patients' outcome including OS and DFS in patients with resected PDAC. This finding was statistically significant in univariate and multivariate analyses after adjustment for standard clinicopathological prognostic factors. Interestingly, this association was restricted to patients who received adjuvant gemcitabine-based therapy. 
Table 3. Brussels cohort: OS and DFS: univariate analysis

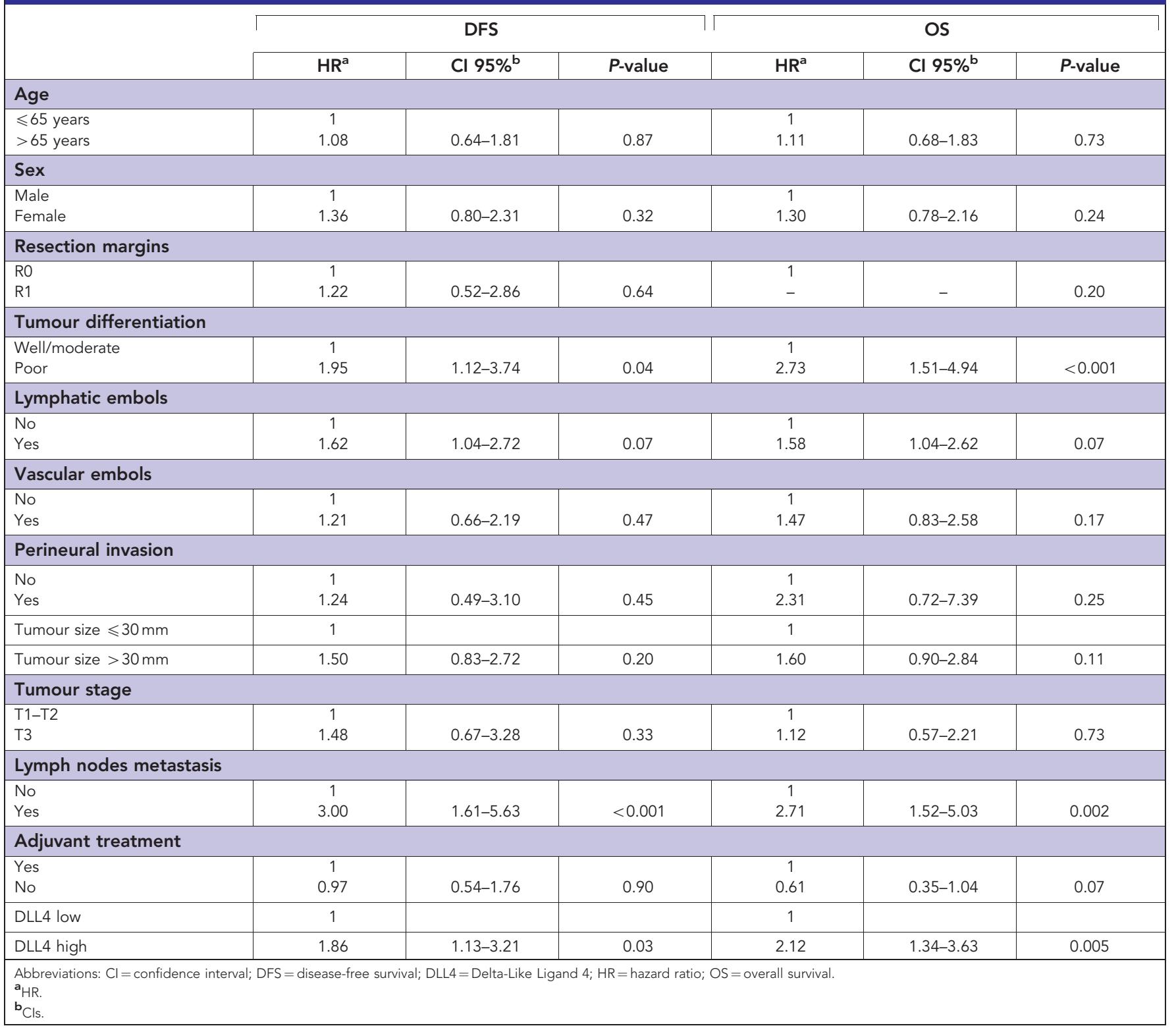

Among patients who received this treatment, DFS and OS were longer in patients with low DLL4 expression than in patients with high DLL4 expression. Conversely, in resected patients who did not received gemcitabine, DLL4 expression was not significantly associated with patients' outcomes. Interaction tests between the expression of DLL4 and the activity of gemcitabine may suggest a predictive value of DLL4. These results were validated in an independent cohort of patients. Collectively, our findings suggest that low DLL4 protein abundance in tumour cells is associated with a clinical benefit of adjuvant gemcitabine therapy. However, due to the small number of patients who did not receive adjuvant therapy, the prognostic value of DLL4 should be confirmed in a larger population.

Furthermore, our study showed that DLL4 IHC expression correlated significantly with the tumour differentiation grade and VEGF protein abundance (VEGF-A and VEGF-B).

Two previous studies reported that low DLL4 expression was a positive prognostic marker in PDAC (Chen et al, 2012; Zhou et al, 2015). However, our study is different on several points. First, these studies did not have accurate data on the adjuvant chemotherapy regimen. Furthermore, in the study by Chen et al (Chen et al, 2012), DLL4 was mainly evaluated in endothelial cells. DLL4 has a dual role in PDAC carcinogenesis through the stimulation of angiogenesis and a direct action on cancer cells. It was clearly established that the Notch ligand DLL4 in vasculature cells may play a key role in tumour angiogenesis via interactions with the VEGF pathway (Li et al, 2007; Lobov et al, 2007), and blocking DLL4 led to non-functional and non-productive neovascularization, which inhibited tumour growth (Noguera-Troise et al, 2006; Ridgway et al, 2006). Moreover, DLL4 overexpression in tumour cells, which was investigated in our study, increased EMT phenotypes, and cancer stem cell frequency in vitro and in vivo (Hoey et al, 2009; Kang et al, 2013). It also played a role in tumour differentiation (Miyamoto et al, 2003; Murtaugh et al, 2003; Mullendore et al, 2009).

In xenograft model of human PDAC, DLL4 in tumour cells with human anti-DLL4 antibody induced pancreatic cell differentiation and cell death, whereas the mouse antibody (anti-mDLL4), which preferentially targets the stroma/vasculature, did not (Yen et al, 2012). The mechanism by which DLL4 expression portends 

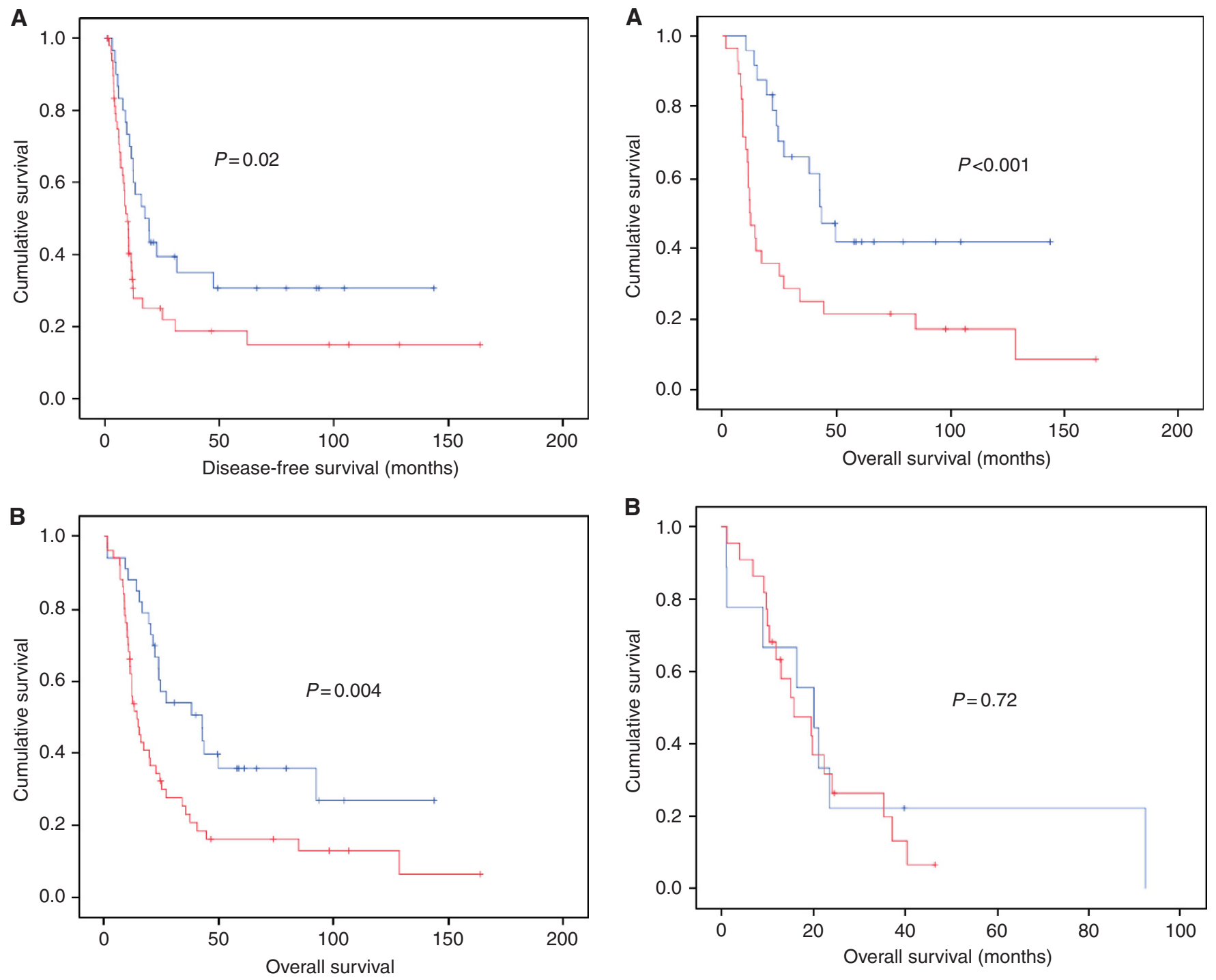

Figure 1. Survival and DLL4 expression. DFS (A) and OS (B) according to DLL4 expression in tumour cells. DLL4 high expressors (red line) and low expressors (blue line).

treatment resistance (a worse treatment outcome) is under investigation. Emerging evidence suggests a molecular and morphological link between chemoresistance and the acquisition of an EMT phenotype (Arumugam et al, 2009). Pancreatic cancer cells resistant to gemcitabine were characterised by a decrease in epithelial markers and the up-regulation of mesenchymal markers. (These features give the cells increased migratory and invasive potential; Shah et al, 2007). A previous study demonstrated that acquisition of the EMT phenotype by gemcitabineresistant pancreatic cancer cells was related to the Notch pathway. Down-regulation of Notch signalling led to a reverse of the EMT phenotype and inhibited invasive properties (Wang et al, 2009). We believe the most likely explanation for our findings is that the low DLL4 abundance in PDAC is associated with reduction of the EMT phenotype, allowing a better activity of the gemcitabine.

Targeting the DLL4/Notch pathway in both tumour cells and endothelial cells is a promising approach to improve outcomes in patients with PDAC. In a pancreatic xenograft tumour model, treatment with combined anti-DLL4 antibody was associated with reduced cancer stem cell frequency, inhibited tumour growth and restored sensitivity to gemcitabine (Yen et al, 2012). A phase I trial

Figure 2. Survival according to attributed treatment. OS curves in DLL4 high (red line) and DLL4 low (blue line) patients who received gemcitabine-based adjuvant chemotherapy $(\mathbf{A})$ and those who did not receive gemcitabine $(\mathbf{B})$.

in patients with previously treated solid tumours, including PDAC, showed interesting results with Demcizumab, an humanised IgG 2 anti-DLL4 antibody (Smith et al, 2014). A randomised phase II trial evaluating as the first-line treatment for patients with locally advanced or metastatic PDAC the demcizumab in combination with gemcitabine and nabpaclitaxel is currently ongoing (Yosemite study, ClinicalTrials.gov). The preliminary results showed an acceptable toxicity profile and encouraging early clinical activity (Hidalgo et al, 2015, 2016).

In contrast with previous studies, Notch1 and Notch3 failed to demonstrate any prognostic or predictive value in this cohort of resected PDAC. Many reasons could explain this. These two studies considered both nuclear and cytoplasmic expression of Notch1 or Notch3 (Mann et al, 2012; Du et al, 2013) even though only nuclear localisation of the protein reflects activation of the pathway. Furthermore, they included both resected and metastatic PDAC (Doucas et al, 2008; Mann et al, 2012). The biology of metastatic PDAC may be different from that of the primary tumour.

In conclusion, DLL4 overexpression was a worse prognostic fact in resected pancreatic cancer patients treated with adjuvant gemcitabine. The results deserve further mechanistic studies to 
Table 4. OS and DFS: multivariate analysis ${ }^{a}$

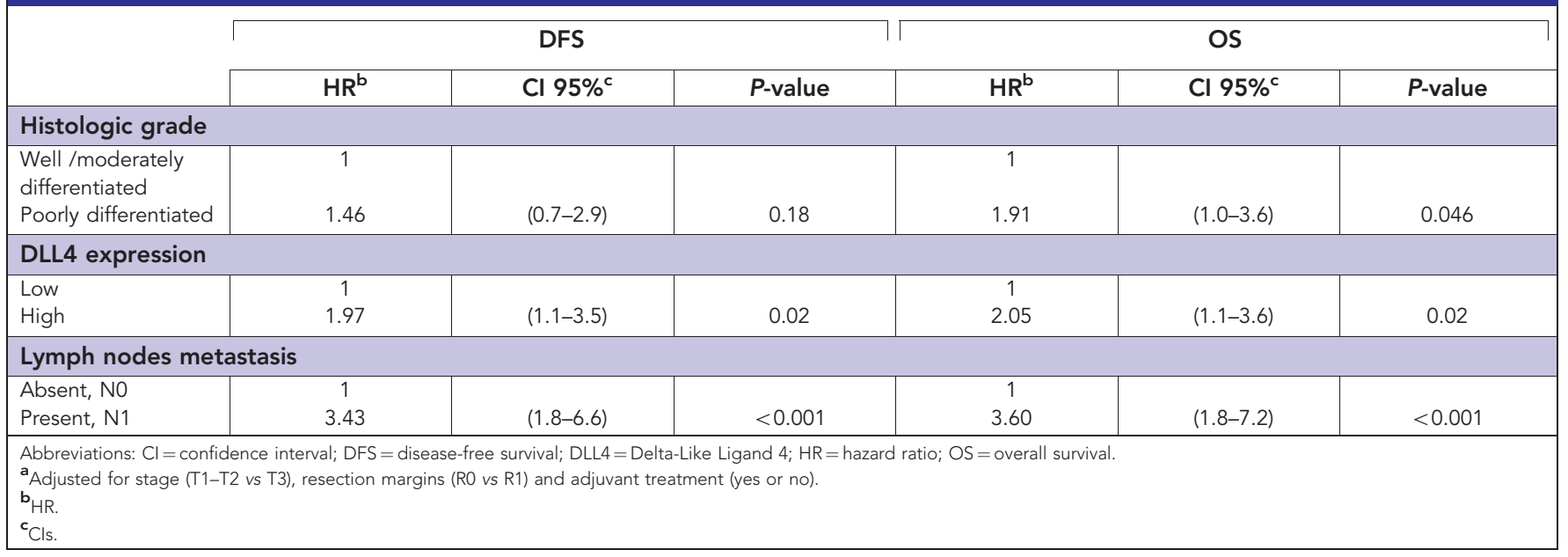

clarify interactions that could exist between DLL4 expression and gemcitabine activity.

\section{ACKNOWLEDGEMENTS}

This work was supported by grants from Plan National Cancer 029-18. The funding source had no role in study design, data collection, data analysis, data interpretation or the writing of the report. FP is a fellow of 'Fonds Erasme'.

\section{CONFLICT OF INTEREST}

The authors declare no conflict of interest.

\section{REFERENCES}

Arumugam T, Ramachandran V, Fournier KF, Wang H, Marquis L, Abbruzzese JL, Gallick GE, Logsdon CD, McConkey DJ, Choi W (2009) Epithelial to mesenchymal transition contributes to drug resistance in pancreatic cancer. Cancer Res 69: 5820-5828.

A phase 1B Study of Gemcitabine and Demcizumab (OMP-21M18) With or Without Abraxane as 1st-line Treatment in Subjects With Locally Advanced or Metastatic Pancreatic Cancer-Full Text View-ClinicalTrials.gov https:// clinicaltrials.gov/ct2/show/NCT01189929?term=demcizumab\&rank=2 (accessed on 18 September 2015).

Chen H-T, Cai Q-C, Zheng J-M, Man X-H, Jiang H, Song B, Jin G, Zhu W, Li Z-S (2012) High expression of delta-like ligand 4 predicts poor prognosis after curative resection for pancreatic cancer. Ann Surg Oncol 19(Suppl 3): S464-S474.

Doucas H, Mann CD, Sutton CD, Garcea G, Neal CP, Berry DP, Manson MM (2008) Expression of nuclear Notch3 in pancreatic adenocarcinomas is associated with adverse clinical features, and correlates with the expression of STAT3 and phosphorylated Akt. J Surg Oncol 97: 63-68.

Dufraine J, Funahashi Y, Kitajewski J (2008) Notch signaling regulates tumor angiogenesis by diverse mechanisms. Oncogene 27: 5132-5137.

Du X, Zhao Y-P, Zhang T-P, Zhou L, Chen G, Cui Q-C, Shi J, Wang T-X, You L, Shu H (2013) Notch1 contributes to chemoresistance to gemcitabine and serves as an unfavorable prognostic indicator in pancreatic cancer. World J Surg 37: 1688-1694.

Hald J, Hjorth JP, German MS, Madsen OD, Serup P, Jensen J (2003) Activated Notch1 prevents differentiation of pancreatic acinar cells and attenuate endocrine development. Dev Biol 260: 426-437.

Hidalgo M, Cooray P, Jameson MB, Carrato A, Parnis F, Jeffery M, Grimison PS, A phase Ib study of the anti-cancer stem cell agent demcizumab (DEM) \& gemcitabine $(\mathrm{GEM})+/$ - paclitaxel protein bound particles (nab-paclitaxel) in pts with pancreatic cancer. | 2015 ASCO Annual Meeting | Abstracts | Meeting Library http://meetinglibrary.asco.org/content/146764-156 (accessed on $18 / 09 / 2015)$.

Hidalgo M, Cooray P, Carrato A, Jameson MB, Parnis F, Jeffery M, Grimison PS, Stagg RJ, Holmgren E, Kapoun AM, Dupont J, Tebbutt NC (2016) A phase $1 \mathrm{~b}$ study of the anti-cancer stem cell agent demcizumab (DEM) and gemcitabine $($ GEM $)+/-$ nab-paclitaxel in patients with pancreatic cancer. J Clin Oncol 34(suppl 4): Vii 341.

Hoey T, Yen W-C, Axelrod F, Basi J, Donigian L, Dylla S, Fitch-Bruhns M, Lazetic S, Park I-K, Sato A, Satyal S, Wang X, Clarke MF, Lewicki J, Gurney A (2009) DLL4 blockade inhibits tumor growth and reduces tumor-initiating cell frequency. Cell Stem Cell 5: 168-177.

Kang M, Jiang B, Xu B, Lu W, Guo Q, Xie Q, Zhang B, Dong X, Chen D, Wu Y (2013) Delta like ligand 4 induces impaired chemo-drug delivery and enhanced chemoresistance in pancreatic cancer. Cancer Lett 330: 11-21.

Kofler NM, Shawber CJ, Kangsamaksin T, Reed HO, Galatioto J, Kitajewski J (2011) Notch signaling in developmental and tumor angiogenesis. Genes Cancer 2: 1106-1116.

Li J-L, Sainson RCA, Shi W, Leek R, Harrington LS, Preusser M, Biswas S, Turley H, Heikamp E, Hainfellner JA, Harris AL (2007) Delta-like 4 Notch ligand regulates tumor angiogenesis, improves tumor vascular function, and promotes tumor growth in vivo. Cancer Res 67: 11244-11253.

Lobov IB, Renard RA, Papadopoulos N, Gale NW, Thurston G, Yancopoulos GD, Wiegand SJ (2007) Delta-like ligand 4 (Dll4) is induced by VEGF as a negative regulator of angiogenic sprouting. Proc Natl Acad Sci USA 104: 3219-3224.

Mann CD, Bastianpillai C, Neal CP, Masood MM, Jones DJL, Teichert F, Singh R, Karpova E, Berry DP, Manson MM (2012) Notch3 and HEY-1 as prognostic biomarkers in pancreatic adenocarcinoma. PLoS One 7: e51119.

Miyamoto Y, Maitra A, Ghosh B, Zechner U, Argani P, Iacobuzio-Donahue CA, Sriuranpong V, Iso T, Meszoely IM, Wolfe MS, Hruban RH, Ball DW, Schmid RM, Leach SD (2003) Notch mediates TGF alpha-induced changes in epithelial differentiation during pancreatic tumorigenesis. Cancer Cell 3: 565-576.

Mullendore ME, Koorstra J-B, Li Y-M, Offerhaus GJ, Fan X, Henderson CM, Matsui W, Eberhart CG, Maitra A, Feldmann G (2009) Ligand-dependent Notch signaling is involved in tumor initiation and tumor maintenance in pancreatic cancer. Clin Cancer Res 15: 2291-2301.

Murtaugh LC, Stanger BZ, Kwan KM, Melton DA (2003) Notch signaling controls multiple steps of pancreatic differentiation. Proc Natl Acad Sci USA 100: 14920-14925.

Noguera-Troise I, Daly C, Papadopoulos NJ, Coetzee S, Boland P, Gale NW, Lin HC, Yancopoulos GD, Thurston G (2006) Blockade of Dll4 inhibits tumour growth by promoting non-productive angiogenesis. Nature $\mathbf{4 4 4}$ 1032-1037.

Oishi H, Sunamura M, Egawa S, Motoi F, Unno M, Furukawa T, Habib NA, Yagita H (2010) Blockade of delta-like ligand 4 signaling inhibits both growth and angiogenesis of pancreatic cancer. Pancreas 39: 897-903. 
Patel NS, Li J-L, Generali D, Poulsom R, Cranston DW, Harris AL (2005) Up-regulation of delta-like 4 ligand in human tumor vasculature and the role of basal expression in endothelial cell function. Cancer Res 65: $8690-8697$.

Ridgway J, Zhang G, Wu Y, Stawicki S, Liang W-C, Chanthery Y, Kowalski J, Watts RJ, Callahan C, Kasman I, Singh M, Chien M, Tan C, Hongo J-AS, de Sauvage F, Plowman G, Yan M (2006) Inhibition of Dll4 signalling inhibits tumour growth by deregulating angiogenesis. Nature $\mathbf{4 4 4}$ : 1083-1087.

Sahlgren C, Gustafsson MV, Jin S, Poellinger L, Lendahl U (2008) Notch signaling mediates hypoxia-induced tumor cell migration and invasion. Proc Natl Acad Sci USA 105: 6392-6397.

Scehnet JS, Jiang W, Kumar SR, Krasnoperov V, Trindade A, Benedito R, Djokovic D, Borges C, Ley EJ, Duarte A, Gill PS (2007) Inhibition of Dll4mediated signaling induces proliferation of immature vessels and results in poor tissue perfusion. Blood 109: 4753-4760.

Shah AN, Summy JM, Zhang J, Park SI, Parikh NU, Gallick GE (2007) Development and characterization of gemcitabine-resistant pancreatic tumor cells. Ann Surg Oncol 14: 3629-3637.

Smith DC, Eisenberg PD, Manikhas G, Chugh R, Gubens MA, Stagg RJ, Kapoun AM, Xu L, Dupont J, Sikic B (2014) A phase I dose escalation and expansion study of the anticancer stem cell agent demcizumab
(anti-DLL4) in patients with previously treated solid tumors. Clin Cancer Res 20: 6295-6303.

Wang Z, Li Y, Kong D, Banerjee S, Ahmad A, Azmi AS, Ali S, Abbruzzese JL, Gallick GE, Sarkar FH (2009) Acquisition of epithelial-mesenchymal transition phenotype of gemcitabine-resistant pancreatic cancer cells is linked with activation of the notch signaling pathway. Cancer Res 69: 2400-2407.

Yen W-C, Fischer MM, Hynes M, Wu J, Kim E, Beviglia L, Yeung VP, Song X, Kapoun AM, Lewicki J, Gurney A, Simeone DM, Hoey T (2012) Anti-DLL4 has broad spectrum activity in pancreatic cancer dependent on targeting DLL4-Notch signaling in both tumor and vasculature cells. Clin Cancer Res 18: 5374-5386.

Zhou L, Yu L, Ding G, Chen W, Zheng S, Cao L (2015) Overexpressions of DLL4 and CD105 are associated with poor prognosis of patients with pancreatic ductal adenocarcinoma. Pathol Oncol Res 21: $1141-1147$.

This work is published under the standard license to publish agreement. After 12 months the work will become freely available and the license terms will switch to a Creative Commons AttributionNonCommercial-Share Alike 4.0 Unported License.

Supplementary Information accompanies this paper on British Journal of Cancer website (http://www.nature.com/bjc) 